\title{
Torrefação e carbonização de briquetes de resíduos do processamento dos grãos de café
}

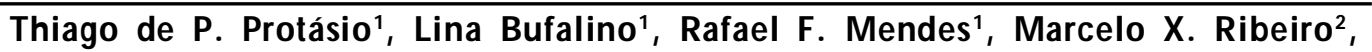 \\ Paulo F. Trugilho ${ }^{1}$ \& Edson R. da S. Leite ${ }^{1}$
}

\begin{abstract}
RESU M 0
O bjetivou-se, nesse trabalho, avaliar os briquetes dos resíduos do processamento dos grãos de café submetidos aos processos de carbonização e torrefação. Os briquetes foram carbonizados utilizandose taxa de aquecimento de $1,67 \stackrel{\circ}{\circ} \mathrm{C} \mathrm{min}^{-1} \mathrm{com}$ temperatura inicial de $50 \stackrel{\circ}{\circ} \mathrm{C}$ e final de $450 \stackrel{\circ}{\circ} \mathrm{C}$, por $30 \mathrm{~min}$. A torrefação dos briquetes foi realizada em uma mufla em duas taxas de aquecimento: 1,5 e $3,0 \stackrel{\circ}{\circ} \mathrm{min}^{-1}$ até $250 \stackrel{\circ}{ } \mathrm{C}$, temperatura mantida durante $60 \mathrm{~min}$. Foram determinados os rendimentos em briquetes torrificados e carbonizados, em líquido pirolenhoso, em gases não condensáveis e em carbono fixo. Para todos os briquetes foram quantificados os teores de carbono fixo, cinzas, voláteis, dos componentes elementares (C, H, N, S, O ), o poder calorífico superior, a densidade aparente e energética e a resistência à compressão diametral. $0 \mathrm{~s}$ briquetes carbonizados apresentaram maior potencial energético devido aos elevados teores de carbono fixo e elementar e poder calorífico, porém baixa resistência mecânica. Os briquetes torrificados nas duas taxas de aquecimento consideradas apresentaram características e propriedades energéticas semelhantes mas densidade energética inferior em relação aos briquetes carbonizados e in natura.
\end{abstract}

Palavras-chave: carbono, pirólise, energia, tratamento térmico

\section{Torrefaction and carbonization of briquettes made with residues from coffee grain}

\begin{abstract}
ABST RACT
This research aimed to evaluate the briquettes made with residues from processing of coffee grain submitted to carbonization and torrefaction. The briquettes were carbonized at a heating rate of $1.67 \stackrel{\circ}{\circ} \mathrm{min}^{-1} \mathrm{with}$ initial temperature of $50 \stackrel{\circ}{ } \mathrm{C}$ and final of $450 \stackrel{\circ}{\circ}$, which was kept during $30 \mathrm{~min}$. The torrefaction of the

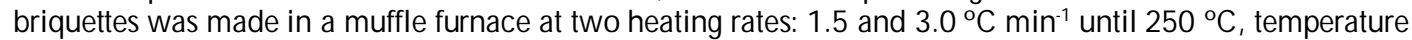
kept during $60 \mathrm{~min}$. The yields in torrefied and carbonized briquettes, pyroligneous liquor, non-condensable gases and fixed carbon were determined. For all briquettes the fixed carbon, ash, volatile and elemental components $(\mathrm{C}, \mathrm{H}, \mathrm{N}, \mathrm{S}, \mathrm{O})$ contents and higher heating value, apparent and energetic density and resistance to diametric compression were quantified. The carbonized briquette presented high energetic potential due to higher fixed and elemental carbon content and heating value, but had low mechanical resistance. The briquettes torrified at the two considered heating rates presented similar energetic properties and characteristics, but lower energetic density than carbonized and fresh briquettes.
\end{abstract}

Key words: carbon, pyrolysis, energy, heat treatment

\footnotetext{
${ }^{1}$ Universidade Federal de Lavras, D epartamento de Ciências Florestais, Setor de Ciência e Tecnologia da Madeira, Caixa Postal 3037, CEP 37200-000, Lavras, MG, Brasil. E-mail: depaulaprotasio@gmail.com; linabufalino@yahoo.com.br; rafaelfarinassi@gmail.com; trugilho@dcf.ufla.br; edsonrubens.ufla@gmail.com

${ }^{2}$ U niversidade Federal do Piauí (U FPI), Câmpus Professora Cinobelina Elvas, Departamento de Engenharia, Bom Jesus, Piauí, Brasil, CEP 64900-000, Bom Jesus, PI, Brasil . E-mail: marceloxisto@hotmail.com
} 


\section{INTRODUÇÃO}

A utilização da biomassa como fonte de energia é uma das opções para se mitigar os malefícios do aquecimento global. Esta biomassa pode ser obtida por duas rotas principais, culturas energéticas ou resíduos lignocelulósicos provenientes de atividades agroflorestais, enquanto a segunda forma oferece a vantagem de destinar adequadamente materiais potenciais poluidores do meio ambiente.

Dentre os resíduos agrícolas a casca de café, proveniente do beneficiamento do grão, pode ser destacada como matériaprima com grande potencial, visto que é produzido em grande escala no Brasil, maior produtor de café do mundo. Em 2011 o País colheu entre 41,89 e 44,73 milhões de sacas de 60 quilos do produto beneficiado em uma área estimada de 2.280,6 mil hectares (CONAB, 2011) sendo que a produção de resíduos do processamento do café pode chegar a $50 \%$ da colheita (Rocha et al., 2006).

Dentre as formas de aproveitamento dos resíduos lignocelulósicos a briquetagem é um processo bastante eficiente para aumentar a densidade energética da biomassa (Protásio et al., 2011a); no entanto, a comercialização de briquetes, sobretudo para consumo doméstico, ainda não é difundida no Brasil. A expansão deste mercado se torna um desafio técnico, pois é necessário que se produzam briquetes com alto padrão de qualidade e maior desempenho energético.

A torrefação e a carbonização desses produtos podem ser alternativas para melhorar sua qualidade e comercialização uma vez que tratamentos térmicos da biomassa resultam em aumento da densidade energética e diminuição da umidade (Prins et al., 2006). A torrefação consiste em tratar termicamente a biomassa entre $225 \mathrm{e} 300^{\circ} \mathrm{C}$ em atmosfera inerte ou não oxidante principalmente para que ocorra a degradação das hemiceluloses, responsáveis, em grande parte, pela absorção de água pela mesma (Prins et al., 2006). Já na carbonização ocorre degradação térmica da biomass, na ausência ou presença controlada de oxigênio, geralmente entre as temperaturas de 350 e $600^{\circ} \mathrm{C}$, embora possa ser realizada considerando-se temperaturas superiores (Demirbas, 2009). Assim, a diferença em relação à torrefação está na temperatura final que será aplicada no briquete.

As hemiceluloses são degradadas entre as temperaturas de 225 e $325^{\circ} \mathrm{C}$, a celulose entre 305 e $375^{\circ} \mathrm{C}$ e a lignina entre 250 e $500^{\circ} \mathrm{C}$ (Shafizadeh, 1985). Desta forma são preservados, em parte, no processo térmico de torrefação, os teores de celulose e lignina.

Adicionalmente, o briquete é convertido em um combustível com maior poder calorífico, menor teor de materiais voláteis, maior teor de carbono fixo, uniformidade em forma e tamanho, menor relação O/C e baixa umidade (Shafizadeh, 1985; Felfli et al., 2005; Prins et al., 2006; Yan et al., 2009; Chen et al., 2011).

Contudo, há uma ausência na literatura de informações relacionadas aos tratamentos térmicos de briquetes dos resíduos lignocelulósicos gerados na cafeicultura. Com base no exposto, o objetivo neste trabalho foi avaliar os briquetes dos resíduos do processamento dos grãos de café submetidos aos tratamentos térmicos de carbonização e torrefação visando ao uso bioenergético.

\section{Material e MÉTOdos}

Para a produção dos briquetes foram utilizados casca e pergaminho de café (Coffea arabica $\mathrm{L}$.) pertencente à variedade Icatu IAC 328, proveniente da fazenda experimental da EPAMIG

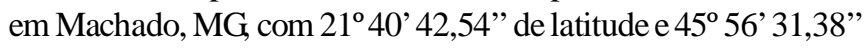
de longitude, cujo plantio foi feito em 1995, em uma área de 0,8 ha.

A biomassa foi moída em um moinho martelo no qual foi acoplada uma peneira com abertura de $2 \mathrm{~mm}$ com vista à redução granulométrica sendo, posteriormente, classificada em peneiras de 40, 60 e 270 mesh (ASTM, 1977).

A compactação dos resíduos foi realizada em uma briquetadeira hidráulica da marca Lippel ${ }^{\circledR}$, modelo LB 32. A biomassa foi secada previamente em estufa a $103 \pm 2{ }^{\circ} \mathrm{C}$. A temperatura utilizada na compactação foi de $120 \pm 5^{\circ} \mathrm{C}$ e a pressão igual a $15 \mathrm{MPa}$, conforme diretrizes de Paula et al. (2011a). Os briquetes foram produzidos com diâmetro de aproximadamente $3 \mathrm{~cm}$ e altura de 6 a $7 \mathrm{~cm}$.

A carbonização dos briquetes foi realizada em um forno elétrico (mufla) utilizando-se uma taxa de aquecimento de 1,67 ${ }^{\circ} \mathrm{C}$ min $^{-1}$ (Trugilho et al., 2001; 2005; Botrel et al., 2007; Protásio et al., 2011c). A temperatura inicial foi de $50^{\circ} \mathrm{C}$ e a temperatura final de $450^{\circ} \mathrm{C}$, mantidas durante 30 min e o tempo total de carbonização foi de $4,5 \mathrm{~h}$.

Realizou-se a torrefação dos briquetes em um forno elétrico utilizando-se duas taxas de aquecimento distintas, ambas com temperatura final de $250^{\circ} \mathrm{C}$.

- Taxa 1: A taxa de aquecimento foi de $1,5^{\circ} \mathrm{C} \min ^{-1}$ até a temperatura de $250^{\circ} \mathrm{C}$, mantida durante $60 \mathrm{~min}$

- Taxa 2: A taxa de aquecimento foi de $3,0^{\circ} \mathrm{C} \mathrm{min}^{-1}$ até $250^{\circ} \mathrm{C}$, mantida durante $60 \mathrm{~min}$

Após a carbonização e a torrefação, contabilizou-se o rendimento gravimétrico em briquetes carbonizados ou torrificados. O cálculo foi feito dividindo-se a massa seca de briquetes carbonizados ou torrificados pela massa seca dos briquetes in natura submetidos ao processo.

O rendimento em líquido pirolenhoso (gases condensáveis oriundos da decomposição térmica da biomassa vegetal) é obtido dividindo-se a massa de líquido obtida pela massa seca de briquetes in natura utilizada no ensaio. Encontrou-se, por diferença, o rendimento em gases não condensáveis, conforme apresentado na Eq. 1 (Trugilho et al., 2001; 2005; Botrel et al., 2007; Protásio et al., 2011c). Determinou-se, ainda, o rendimento em carbono fixo como sendo a multiplicação entre o rendimento gravimétrico em briquetes carbonizados ou torrificados pelo teor de carbono fixo.

$$
\mathrm{RGNC}=100 \%-\mathrm{RGB}-\mathrm{RLP}
$$

sendo:

RGNC - rendimento em gases não condensáveis, \%

RGB - rendimento em briquete carbonizado ou torrificado, $\%$

RLP - rendimento em líquido pirolenhoso, $\%$

Todas as análises foram realizadas para os briquetes in natura, ou seja, não submetidos ao tratamento térmico, tal como para os briquetes carbonizados e torrificados. 
Para a análise elementar dos briquetes as amostras foram moídas e peneiradas tendo-se utilizado, para o ensaio, $2 \mathrm{mg}$ da fração que passou pela peneira de 200 mesh e ficou retida na peneira de 270 mesh. Referida análise foi realizada em um analisador universal da marca Elementar (modelo Vario Micro Cube), sendo quantificados os teores de carbono, hidrogênio, nitrogênio e enxofre (em relação à massa seca da biomassa), conforme realizado por Protásio et al. (2011b). O teor de oxigênio foi obtido por diferença, segundo a Eq. 2 (Bech et al., 2009).

$$
\mathrm{O}=100 \%-\mathrm{C}-\mathrm{H}-\mathrm{N}-\mathrm{S}-\mathrm{CZ}
$$

sendo:
O - teor de oxigênio, \%
$\mathrm{C}$ - teor de carbono, $\%$
$\mathrm{H}$ - teor de hidrogênio, $\%$
$\mathrm{N}$ - teor de nitrogênio, \%
$\mathrm{S}$ - teor de enxofre, $\%$
$\mathrm{Cz}$ - teor de cinzas, $\%$

Procedeu-se à análise química imediata dos briquetes para a quantificação dos teores de carbono fixo, materiais voláteis e cinzas, segundo as diretrizes da norma NBR 8112 (ABNT, 1983). Utilizou-se, visando à quantificação do poder calorífico superior (PCS) dos briquetes, um calorímetro digital da marca IKA C-200, em que o ensaio foi padronizado com a norma NBR 8633 (ABNT, 1984).

Os briquetes foram mantidos em câmara climatizada até estabilização da massa; posteriormente, determinou-se a umidade em base seca dos corpos de prova.

A densidade aparente dos briquetes foi determinada através do método estereométrico. O volume foi calculado considerando-se a forma cilíndrica dos briquetes e se utilizando um paquímetro digital com precisão de $0,01 \mathrm{~mm}$ enquanto a massa foi obtida em uma balança analítica de precisão de $5 \mathrm{mg}$. Determinou-se o diâmetro dos briquetes considerando-se três partes distintas, ou seja, a parte superior e a inferior e o centro. Portanto, para os cálculos de volume tomou-se como base o diâmetro médio dos briquetes (Protásio et al., 2011a).

A densidade energética dos briquetes foi calculada multiplicando-se o poder calorífico superior pelos seus valores de densidade aparente (Protásio et al., 2011a).

Avaliou-se a resistência à tração por compressão diametral dos briquetes segundo as diretrizes da norma NBR 7222 (ABNT, 1994) com algumas adaptações. Os briquetes foram mantidos em câmara climatizada até massa constante e o ensaio foi realizado na Máquina de Ensaio Universal EMIC, modelo DL30000.
$\mathrm{Na}$ avaliação do experimento utilizou-se o delineamento inteiramente casualizado com 4 repetições tendo-se, como fator de variação, os diferentes tipos de briquete (Eq. 3). Para a resistência a compressão e rendimento gravimétrico, utilizaram-se 6 repetições e, para o rendimento gravimétrico, foram considerados 3 tratamentos representados apenas pelos briquetes tratados termicamente. Para a comparação múltipla das médias foi utilizado o teste de Tukey em nível de 0,05 de significância.

$$
Y_{i j}=\mu+t_{i}+e_{i j}
$$

sendo:

$\mathrm{Y}_{\mathrm{ij}}$ - Observação do i-ésimo tipo de briquete (i = 1, 2, 3 e 4) na j-ésima repetição $(\mathrm{j}=1,2,3 \ldots \mathrm{n})$

$\mu$ - Constante inerente a todas as observações

$\mathrm{t}_{\mathrm{i}} \quad$ - Efeito do i-ésimo tipo de briquete $(\mathrm{i}=1,2,3 \mathrm{e} 4)$

$e_{i j}$ - Erro experimental associado à observação $Y_{i j}$, independente e identicamente distribuído de uma Normal com média zero e variância $\sigma^{2}$

\section{RESULTADOS E DISCUSSÃO}

Na Tabela 1 está apresentada a composição granulométrica da biomassa utilizada na produção dos briquetes dos resíduos do processamento dos grãos de café.

Tabela 1. Composição granulométrica da biomassa utilizada

$\begin{array}{cc}\text { Granulometria (mm) } & \text { Composição (\%) } \\ \varnothing \geq 0,425 & 84 \\ 0,425>\emptyset \geq 0,250 & 11 \\ \varnothing<0,250 & 5\end{array}$

Na Tabela 2 se encontram os teores médios dos componentes elementares para os briquetes in natura (BCASCA), torrificados nas taxas 1 (BT1.5) e 2 (BT3.0) e carbonizados (BCARB), bem como o teste de comparação múltipla realizado.

Observou-se que o efeito dos diferentes tipos de briquete foi significativo a $1 \%$ pelo teste $\mathrm{F}$ para os teores de carbono, hidrogênio, nitrogênio, enxofre e oxigênio.

Os briquetes carbonizados apresentaram aproximadamente $56 \%$ de acréscimo no teor de carbono quando comparado com o dos briquetes in natura. Para o teor de hidrogênio os briquetes carbonizados e in natura apresentaram, estatisticamente, o menor e o maior valor médio. Felfli et al. (2005) afirmaram que briquetes termicamente modificados apresentam teores de componentes elementares intermediários entre a biomassa in natura e o carvão vegetal, conforme observado neste trabalho.

Tabela 2. Análise química elementar dos briquetes

\begin{tabular}{cccccccc}
\hline Briquetes & $\mathbf{C ~ ( \% )}$ & $\mathbf{H ~ ( \% )}$ & $\mathbf{0 ~ ( \% )}$ & $\mathbf{N ~ ( \% )}$ & $\mathbf{S ~ ( \% )}$ & $\mathbf{H} / \mathbf{C}$ & $\mathbf{0 / C}$ \\
BCARB & $70,42 \mathrm{c}$ & $3,48 \mathrm{a}$ & $16,22 \mathrm{a}$ & $2,15 \mathrm{a}$ & $0,12 \mathrm{a}$ & 0,04 & 0,23 \\
BT1.5 & $55,86 \mathrm{~b}$ & $5,08 \mathrm{~b}$ & $31,34 \mathrm{~b}$ & $2,40 \mathrm{~b}$ & $0,14 \mathrm{~b}$ & 0,09 & 0,56 \\
BT3.0 & $55,27 \mathrm{~b}$ & $5,04 \mathrm{~b}$ & $31,99 \mathrm{~b}$ & $2,38 \mathrm{~b}$ & $0,14 \mathrm{~b}$ & 0,09 & 0,58 \\
BCASCA & $45,09 \mathrm{a}$ & $5,42 \mathrm{c}$ & $42,89 \mathrm{c}$ & $2,12 \mathrm{a}$ & $0,13 \mathrm{ab}$ & 0,12 & $\mathbf{0}$ \\
\hline CVe (\%) & 1,44 & 1,81 & 3,04 & 2,31 & 4,14 & - & - \\
FC & $656,12^{*}$ & $405,54^{*}$ & $553,47^{*}$ & $31,46 *$ & $5,95^{*}$ & - \\
\hline
\end{tabular}

CVe: coeficiente de variação experimental; Fc: $\mathrm{F}$ calculado; * : significativo a 1\% de probabilidade pelo teste $\mathrm{F}$. Médias seguidas da mesma letra não diferem entre si a 0,05 de significância pelo teste de Tukey 
Altos teores de carbono e hidrogênio e baixos teores de oxigênio são desejáveis quando a biomassa é utilizada como fonte de energia devido às correlações existentes entre esses componentes elementares e o poder calorífico (Huang et al., 2009; Paula et al., 2011a; Protásio et al., 2011b).

Entre os briquetes torrificados não foi possível observar alterações significativas nos teores dos componentes elementares; contudo, ambos apresentaram maior teor de carbono, correspondendo a aproximadamente $23 \%$ de acréscimo, e menores teores de hidrogênio e oxigênio em relação aos briquetes in natura. Felfli et al. (2005) afirmaram que as relações $\mathrm{H} / \mathrm{C} \mathrm{e} \mathrm{O/C} \mathrm{diminuem} \mathrm{com} \mathrm{o} \mathrm{processo} \mathrm{de} \mathrm{torrefação,} \mathrm{conforme}$ observado neste trabalho. Este fato está relacionado à degradação térmica das hemiceluloses, resultando na liberação da maioria dos componentes oxigenados e aromatizados.

Chen et al. (2011) encontraram, para a madeira torrificada na temperatura de $250^{\circ} \mathrm{C}$ e tempo total de $2 \mathrm{~h}$, os valores de 66,73 , $5,84,27,30$ e $0,14 \%$ para os teores de carbono, hidrogênio, oxigênio e nitrogênio, respectivamente, diferindo do encontrado neste trabalho para os briquetes dos resíduos do processamento dos grãos de café torrificados.

Já Felfli et al. (2005) encontraram, para o briquete torrificado de madeira na temperatura de $250^{\circ} \mathrm{C}$ e tempo de $1,5 \mathrm{~h}$, valores de 57,63, 6,00 e 28,47\% para os teores de carbono, hidrogênio e oxigênio, respectivamente, resultados que demonstram a influência da composição química da biomassa, da taxa de aquecimento e do tempo total na composição química elementar do combustível submetido ao processo térmico de torrefação.

Brand (2010), Paula et al. (2011a) e Oliveira et al. (2010) encontraram valores superiores de nitrogênio em relação aos briquetes do presente trabalho para madeira de folhosas, resíduos lignocelulósicos e carvão vegetal de Eucalyptus pellita, respectivamente.

Observam-se baixos teores de enxofre para todos os briquetes produzidos sendo que o menor valor foi encontrado para o briquete carbonizado. Estatisticamente, os briquetes torrificados apresentaram os maiores teores de nitrogênio.

A comparação dos teores de nitrogênio e enxofre dos briquetes dos resíduos dos grãos de café com outros biocombustíveis estudados na literatura demonstra que $o$ processo é ambientalmente vantajoso.

Assim como o nitrogênio, altos teores de enxofre podem resultar em poluição ambiental, como a formação de óxidos de nitrogênio (NOx) e enxofre (SOx) tóxicos, formação de chuva ácida e corrosão após a combustão (Bilgen \& Kaygusuz, 2008; Bech et al., 2009). Além disto, o nitrogênio não apresenta correlação positiva com o poder calorífico superior (Huang et al., 2009).

$\mathrm{Na}$ Figura 1 se apresentam os valores médios dos teores de carbono fixo, materiais voláteis e cinzas e do poder calorífico superior (PCS) dos briquetes carbonizados (BCARB), torrificados nas taxas 1 (BT1.5) e 2 (BT3.0) e in natura (BCASCA).

Observa-se que, estatisticamente, o briquete in natura apresentou estatisticamente o menor teor de carbono fixo, observando-se o inverso para o teor de materiais voláteis. $\mathrm{O}$ processo de pirólise utilizado resultou em um aumento de aproximadamente $185 \%$ no teor de carbono fixo do briquete

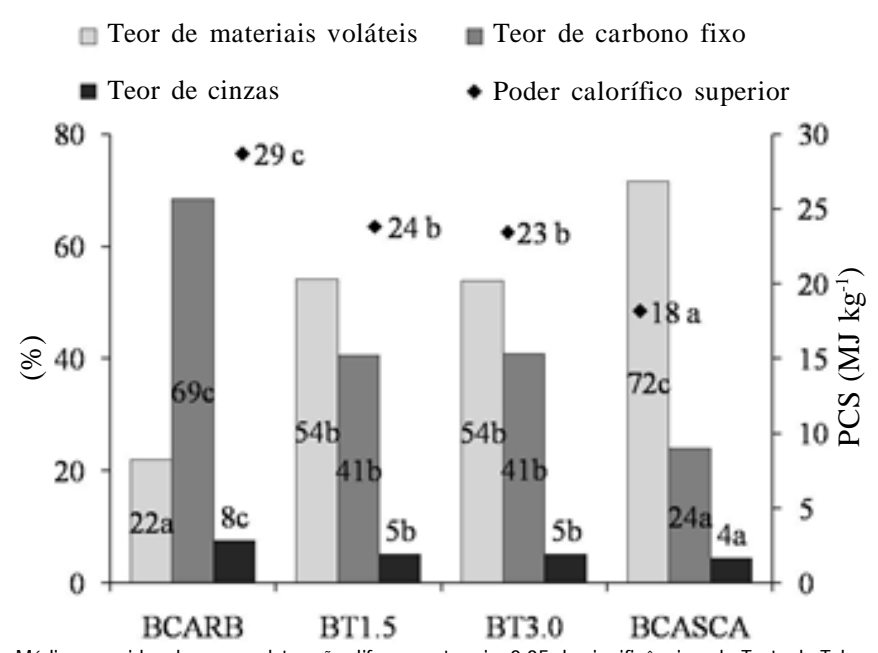

Médias seguidas da mesma letra não diferem entre si a 0,05 de significância pelo Teste de Tukey

Figura 1. Análise química imediata e poder calorífico superior (PCS) dos briquetes

carbonizado em relação ao briquete in natura. Os briquetes torrificados sinalizaram, estatisticamente, o mesmo teor de carbono fixo, correspondendo a um acréscimo médio de $70 \%$ quando comparado ao briquete in natura; os resultados encontrados demonstram que a taxa de aquecimento não influenciou na composição química imediata dos briquetes torrificados.

Combustíveis com altos teores de carbono fixo e baixos teores de materiais voláteis tendem a se queimar mais lentamente, ou seja, eles poderão requerer longo tempo de residência na fornalha para a queima total, quando comparados com combustíveis que possuam baixo índice de carbono fixo (Brand, 2010). Por outro lado, a principal vantagem do processo de carbonização é a concentração de carbono no combustível para uso siderúrgico como agente de dupla finalidade (redução do minério de ferro e fornecimento de energia para o alto forno).

Trugilho et al. (2005) encontraram, avaliando o carvão vegetal de clones de Eucalyptus em diferentes posições radiais de amostragem, teor de carbono fixo médio de $69 \%$, corroborando com o observado para o carvão vegetal de briquete de resíduos do processamento dos grãos de café; este resultado é um indicativo do potencial de uso deste biocombustível sólido na siderurgia.

Quanto ao teor de materiais voláteis, Trugilho et al. (2001) encontraram média de $20,46 \%$ para o carvão vegetal de diferentes clones de Eucalyptus, sendo 7,43\% inferior ao encontrado neste trabalho para o carvão vegetal do briquete de resíduos de café; no entanto, o teor médio de voláteis determinado por Paula et al. (2011a) para diferentes tipos de resíduos lignocelulósicos $(78,56 \%)$ é superior ao constatado neste trabalho para os briquetes de resíduos de café in natura e evidenciam o potencial energético desse material lignocelulósico.

A análise do teor de cinzas nos combustíveis de biomassa é imprescindível na avaliação energética desses materiais, uma vez que altos teores de cinza contribuem para a redução do poder calorífico, visto que os materiais minerais não participam do processo de combustão (Gonçalves et al., 2009; Brand, 2010; Paula et al., 2011a; Protásio et al., 2011b). Além do mais, alto 
teor de cinza no carvão pode provocar o acúmulo de impurezas no centro das peças do metal solidificado, acarretando variações nas propriedades físicas, químicas e mecânicas do ferro gusa ou ferro liga.

Observa-se que o briquete in natura e o carbonizado apresentaram o menor e o maior teor de cinza, respectivamente, como consequência do processo de pirólise que ocasiona uma concentração tanto de carbono fixo quanto de cinzas na biomassa submetida ao tratamento térmico.

Comumente são encontrados, na literatura, baixos teores de cinza $(0,16$ a 2,6\%) para o carvão vegetal de vários clones e espécies de Eucalyptus (Trugilho et al., 2001; 2005; Botrel et al., 2007; Oliveira et al., 2010), sendo que esses valores são muito inferiores ao valor médio encontrado para o carvão vegetal de briquete de resíduos do processamento dos grãos de café.

O valor médio de cinzas encontrado por Protásio et al. (2011b) para a casca e o pergaminho de café de 4,92\% é superior, contudo, ao encontrado para o briquete in natura. Já Paula et al. (2011a) constataram, avaliando o pergaminho do fruto do cafeeiro, teor de cinzas de 1,46\%. Arantes et al. (2008) encontraram teor de cinzas de $9,0 \%$ para a casca de café carbonizada, valor este superior, portanto, ao encontrado neste trabalho para o briquete carbonizado. É provável que o local de origem e o sistema de cultivo empregado nas lavouras de café tenham influenciado nos resultados encontrados para a composição química imediata dos resíduos avaliados.

Observa-se tendência de maiores valores de poder calorífico superior estarem associados aos maiores valores de carbono fixo, observando-se o contrário para o teor de materiais voláteis. Logo, um acréscimo do teor de carbono fixo e um decréscimo no teor de materiais voláteis proporcionam aumento no poder calorífico superior (Vale et al., 2001; Protásio et al., 2011c) haja vista que, associada ao carbono, é a entalpia que determina o valor calórico dos combustíveis submetidos ao tratamento térmico. Apesar do material volátil também possuir carbono sua fração no briquete carbonizado é inferior ao carbono fixo (Figura 1).

Nota-se que o incremento médio no poder calorífico superior dos briquetes torrificados foi de $30 \%$ se comparado ao do briquete in natura. Já para o briquete carbonizado este incremento foi de aproximadamente $58 \%$. Segundo Chen et al. (2011), a temperatura de $250{ }^{\circ} \mathrm{C}$ e um tempo de torrefação superior a $1 \mathrm{~h}$ são recomendados para maximizar o poder calorífico da biomassa com menor perda de massa do combustível.

Os briquetes torrificados apresentaram, em média, 3\% de umidade em base seca e os briquetes in natura e carbonizados 7 e $8 \%$, respectivamente. A diminuição do teor de umidade dos briquetes torrificados se deve, provavelmente, à degradação das hemiceluloses, que são os componentes químicos mais reativos presentes na biomassa vegetal (Prins et al., 2006), sendo esta uma característica vantajosa do processo de torrefação de vez que, quanto maior a umidade menor o valor calórico do combustível (Brand, 2010).

Os valores médios para densidade aparente e energética dos briquetes in natura (BCASCA) torrificados nas taxas de aquecimento 1 (BT1.5) e 2 (BT3.0) e carbonizados (BCARB) estão apresentados na Figura 2.

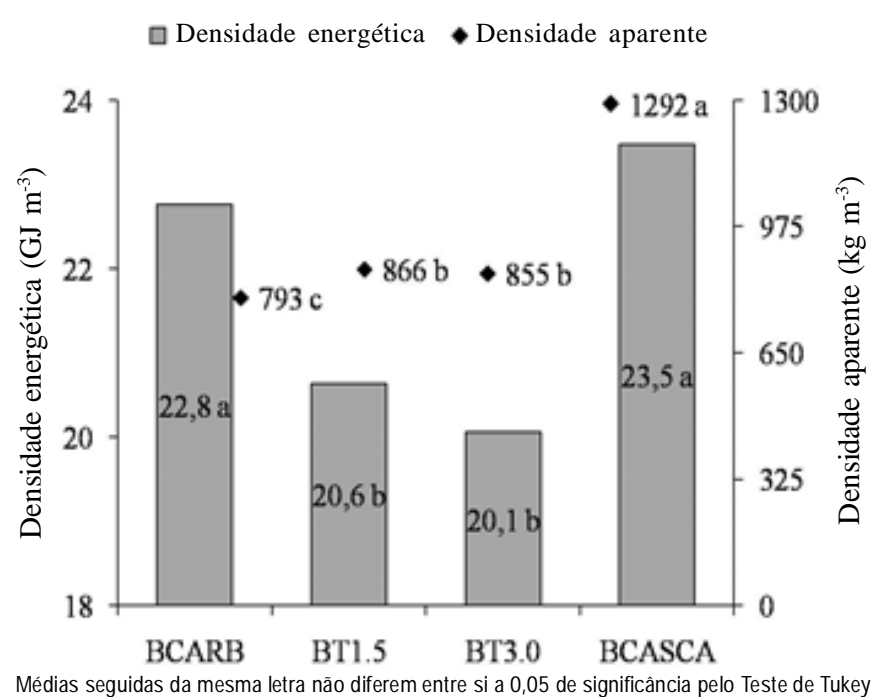

Figura 2. D ensidade aparente e energética dos briquetes

Visando à utilização energética dos combustíveis de biomassa, é desejável alta densidade energética, ou seja, maior quantidade de energia por unidade de volume. Observa-se que o briquete carbonizado e o in natura apresentaram, estatisticamente, os maiores valores para densidade energética, em virtude da alta densidade aparente dos briquetes in natura quando comparada com a do briquete carbonizado, o que ocasiona alta densidade energética, mesmo o combustível apresentando o menor valor calórico (Figura 1). Já os briquetes torrificados apresentaram, estatisticamente, os menores valores de densidade energética.

Os resultados encontrados na literatura para densidade energética de espécies arbóreas comumente utilizadas na geração de energia evidenciam o potencial de utilização dos briquetes dos resíduos do processamento dos grãos de café.

Lima et al. (2011) e Vale et al. (2001) encontraram valores de densidade energética de 9,29 e 13,27 GJ m³ para Eucalyptus benthamii e espécies do cerrado, respectivamente, valores esses inferiores aos obtidos para todos os briquetes deste trabalho.

Quanto à densidade aparente os briquetes carbonizados apresentaram o menor valor médio e os briquetes in natura o maior. Os briquetes torrificados sinalizaram, estatisticamente, posição intermediária. Produtos de alta densidade são vantajosos do ponto de vista de transporte, armazenamento e manuseio devido à otimização e à logística do processo.

A densidade aparente observada por Paula et al. (2011b) para os briquetes de vários tipos de resíduos lignocelulósicos, foi inferior à observada neste trabalho para o briquete de casca de café in natura. Para o briquete de serragem de Pinus sp. Furtado et al. (2010) encontraram densidade aparente de 1260 $\mathrm{kg} \mathrm{m}^{-3}$, diferindo em apenas $2,54 \%$ do encontrado neste trabalho para o briquete dos resíduos do processamento dos grãos de café, cujos resultados demonstram o potencial energético dos briquetes avaliados neste trabalho.

Observou-se que, estatisticamente, os briquetes torrificados nas duas taxas consideradas apresentaram o mesmo valor médio para o rendimento gravimétrico (em média 67,56\%); já o briquete carbonizado apresentou rendimento gravimétrico médio de $39,26 \%$. 
O rendimento em líquido pirolenhoso e em gases não condensáveis da carbonização dos briquetes foi de 40,67 e $20,07 \%$, respectivamente, enquanto para os briquetes torrificados os rendimentos em líquido pirolenhoso e em gases não condensáveis foram de 22,09 e 16,44\% e de 11,15 e 15,58\% para as taxas $1 \mathrm{e} 2$, respectivamente.

Botrel et al. (2007) e Trugilho et al. (2005) observaram rendimento gravimétrico médio de 35,03 e $40 \%$ respectivamente para vários clones de Eucalyptus. Os resultados encontrados para o rendimento em briquetes carbonizados são um indicativo do potencial de utilização do carvão vegetal dos resíduos do processamento dos grãos de café.

Os rendimentos médios em carbono fixo encontrados para os briquetes torrificados nas taxas 1 e 2 foram de 27,12 e 27,95, respectivamente; já os briquetes carbonizados apresentaram rendimento em carbono fixo médio de $26,90 \%$. Observa-se que, em média, os rendimentos em carbono fixo encontrados para os briquetes submetidos ao tratamento térmico no forno mufla foram semelhantes.

Para vários clones de Eucalyptus o rendimento médio em carbono fixo mencionado na literatura é de aproximadamente 26\% (Trugilho et al., 2005; Botrel et al., 2007), corroborando com o encontrado no presente trabalho para os briquetes carbonizados e torrificados.

Na Figura 3 se encontram os valores médios obtidos para o ensaio de resistência à tração por compressão diametral dos briquetes produzidos.

Estatisticamente, os briquetes carbonizados apresentaram a menor resistência a compressão, consequência da redução

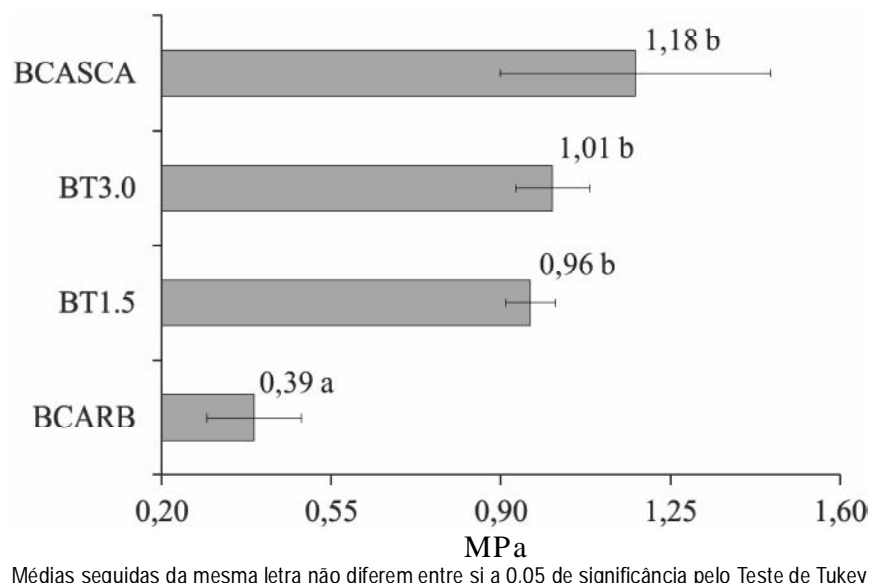

Figura 3. Resistência à tração por compressão diametral dos briquetes

da densidade aparente (Paula et al., 2011b) oriunda do processo de pirólise. Além disto, a biomassa carbonizada é mais friável em relação à biomassa torrificada, o que pode contribuir para um decréscimo da resistência mecânica.

A resistência mecânica dos briquetes é um indicativo importante de sua durabilidade e aplicabilidade em sistemas de geração de energia, indicando desvantagem do processo de carbonização. O carvão vegetal destinado aos altos fornos siderúrgicos deve apresentar elevada resistência à abrasão.

\section{Conclusões}

1. O briquete carbonizado apresenta potencial energético em razão dos maiores teores de carbono fixo e elementar e poder calorífico; apesar disto, esses briquetes apresentaram baixa resistência mecânica e densidade energética estatisticamente iguais às dos briquetes in natura.

2. De maneira geral, os briquetes torrificados nas duas taxas de aquecimento consideradas apresentaram características e propriedades energéticas semelhantes, mas com densidade energética inferior em relação aos briquetes carbonizados e in natura.

\section{LITERATURA CITADA}

ABNT - Associação Brasileira de Normas Técnicas.. NBR 8112: Análise imediata: Material volátil, cinzas, carbono fixo. Rio de Janeiro: ABNT, 1983. 6p.

ABNT - Associação Brasileira de Normas Técnicas. NBR 8633: Carvão vegetal - determinação do poder calorífico. Rio de Janeiro: ABNT, 1984. 13p.

ABNT - Associação Brasileira de Normas Técnicas. NBR 7222: Argamassa e concreto. Determinação da resistência à tração por compressão diametral de corpos-de-prova cilíndricos: Método de ensaio. Rio de Janeiro: ABNT, 1994. 3p.

Arantes, M. D.; Mendes, L. M.; Rabelo, G. F.; Silva, J. R. M.; Mori, F. A.; Barbosa, A. M. Gaseificação de materiais lignocelulósicos para a geração de energia elétrica. Ciência Florestal, v.18, p.525-533, 2008.

ASTM - American Society for Testing Materials. ASTM D 1762: Standard method for chemical analyses of wood charcoal. Philadelphia: ASTM International, 1977. 1042p.

Bech, N.; Jensen, P. A.; Dam-Johansen, K. Determining the elemental composition of fuels by bomb calorimetry and the inverse correlation of HHV with elemental composition. Biomass and Bioenergy, v.33, p.534-537, 2009.

Bilgen, S.; Kaygusuz, K. The calculation of the chemical exergies of coal-based fuels by using the higher heating values. Applied Energy, v.85, p.776-785, 2008.

Botrel, M. C. G.; Trugilho, P. F.; Rosado, S. C. S.; Silva, J. R. M. Melhoramento genético das propriedades do carvão vegetal de Eucalyptus. Revista Árvore, v.31, p.391-398, 2007.

Brand, M. A. Energia de biomassa florestal. 1.ed. Rio de Janeiro: Interciência, 2010. 131p.

Chen, W. H.; Hsu, H. C.; Lu, K. M.; Lee, W. J.; Lin, T. C. Thermal pretreatment of wood (Lauan) block by torrefaction and its influence on the properties of the biomass. Energy, v.36, p.3012-3021, 2011.

CONAB - Companhia Nacional de Abastecimento. Avaliação da safra agrícola cafeeira $-1^{\text {a }}$ Estimativa - Janeiro/2011. Brasília: CONAB, 2011.25p.

Demirbas, A. Biorefineries: Urrent activities and future developments. Energy Conversion and Management, v.50, p.2782-2801, 2009.

Felfli, F. F.; Luengo, C. A.; Suárez, J. A.; Beatón, P. A. Wood briquette torrefaction. Energy for Sustainable Development, v.9, p.19-22, 2005. 
Furtado, T. S.; Valin, M.; Brand, M. A.; Bellote, A. F. J. Variáveis do processo de briquetagem e qualidade de briquetes de biomassa florestal. Pesquisa Florestal Brasileira, v.30, p.101106, 2010.

Gonçalves, J. E.; Sartori, M. M. P.; Leão, A. L. Energia de briquetes produzidos com rejeitos de resíduos sólidos urbanos e madeira de Eucalyptus grandis. Revista Brasileira de Engenharia Agrícola e Ambiental, v.13, p.657-661, 2009.

Huang, C.; Han, L.; Yang, Z.; Liu, X. Ultimate analysis and heating value prediction of straw by near infrared spectroscopy. Waste Management, v.29, p.1793-1797, 2009.

Lima, E. A.; Silva, H. D.; Lavoranti, O. J. Caracterização dendroenergética de árvores de Eucalyptus benthamii. Pesquisa Florestal Brasileira, v.31, p.09-17, 2011.

Oliveira, A. C.; Caneiro, A. C. O.; Vital, B. R.; Almeida, W.; Pereira, B. L. C.; Cardoso, M. T. Parâmetros de qualidade da madeira e do carvão vegetal de Eucalyptus pellita F. Muell. Scientia Forestalis, v.38, p.431-439, 2010.

Paula, L. E. R.; Trugilho, P. F.; Napoli, A.; Bianchi, M. L. Characterization of residues from plant biomass for use in energy generation. Cerne, v.17, p.237-246, 2011a.

Paula, L. E. R.; Trugilho, P. F.; Rezende, R. N.; Assis, C. O. Produção e avaliação de briquetes de resíduos lignocelulósicos. Pesquisa Florestal Brasileira, v.31, p.103112, 2011b.

Prins, M. J.; Ptasinski, K. J.; Janssen, F. J. J. G. Torrefaction of wood. Part 2. Analysis of products. Journal of Analytical and Applied Pyrolysis, v.77, p.35-40, 2006.

Protásio, T. P.; Alves, I. C. N.; Trugilho, P. F.; Silva, V. O.; Baliza, A. E. R. Compactação de biomassa vegetal visando à produção de biocombustíveis sólidos. Pesquisa Florestal Brasileira, v.31, p.273-283, 2011a.
Protásio, T. P.; Bufalino, L.; Tonoli, G. H. D.; Couto, A. M.; Trugilho, P. F.; Guimarães Júnior, M. Relação entre o poder calorífico superior e os componentes elementares e minerais da biomassa vegetal. Pesquisa Florestal Brasileira, v.31, p.122-133, 2011b.

Protásio, T. P.; Santana, J. D. P.; Guimarães Neto, R. M.; Guimarães Júnior, J. B; Trugilho, P. F.; Ribeiro, I. B. Avaliação da qualidade do carvão vegetal de Qualea parviflora. Pesquisa Florestal Brasileira, v.31, p.295-307, 2011c.

Rocha, F. C.; Garcia, R.; Freitas, A. W. P.; Souza, A. L. S.; Gobbi, K. F.; Valadares Filho, S. C.; Tonucci, R. G.; Rocha, G. C. Casca de café em dietas para vacas em lactação: consumo, digestibilidade, produção e composição de leite. Revista Brasileira de Zootecnia, v.35, p.2163-2171, 2006.

Shafizadeh, F. Pyrolytic reactions and products of biomass. In: Overend, R. P.; Milne, T. A.; Mudge, L. K. (ed.) Fundamentals of Biomass Thermochemical Conversion. London: Elsevier, 1985. Cap.6, p.183-217.

Trugilho, P. F.; Lima, J. T.; Mori, F. A.; Lino, A. L. Avaliação de clones de Eucalyptus para a produção de carvão vegetal. Cerne, v.7, p.104-114, 2001.

Trugilho, P. F.; Silva, J. R. M.; Mori, F. A.; Lima, J. T.; Mendes, L. M.; Mendes, L. F. B. Rendimentos e características do carvão vegetal em função da posição radial de amostragem em clones de Eucalyptus. Cerne, v.11, p.178-186, 2005.

Vale, A. T.; Costa, A. F.; Gonçalez, J. C.; Nogueira, M. Relações entre a densidade básica da madeira, o rendimento e a qualidade do carvão vegetal de espécies do cerrado. Revista Árvore, v.25, p.89-95, 2001.

Yan, W.; Acharjee, T. C.; Coronella, C. J.; Vasquez, V. R. Thermal pretreatment of lignocellulosic biomass. Environmental Progress \& Sustainable Energy, v.28, p.435-440, 2009. 